\title{
Policy tools to address scale mismatches: insights from U.S. forest governance
}

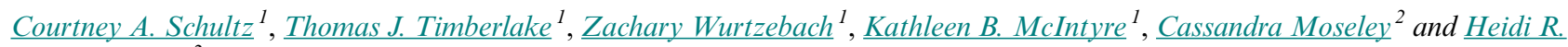 \\ $\underline{\text { Huber-Stearns }}^{2}$
}

\begin{abstract}
Recent literature has highlighted the growing array of scale mismatches in environmental governance and offered policy design principles for improved governance approaches. A next step is to develop our understanding of specific policy tools that can address scale mismatches. This paper reviews the range and importance of scale-related challenges and solutions in environmental governance, situating this discussion in the context of forest governance. We then tackle the matter of policy tools to address scale mismatches, by synthesizing findings from recent policy research on two contemporarily important issues in forest governance, collaborative landscape restoration and multilevel monitoring for ecological integrity, each of which presents distinct challenges related to scale matching and coordination. The research suggests that policy innovations are supporting greater scale sensitivity, through specific legal mandates that require scale considerations and promotion of partnerships and networks. Successful strategies balance requirements to work across scales and levels, with flexibility to tailor approaches to local contexts; our work demonstrates how policy tools can facilitate this in particular contexts. Future research should seek to understand the trade-offs of working at particular scales and continue to explore examples of how design principles for adaptive governance manifest in policy and practice across different contexts.
\end{abstract}

Key Words: adaptive governance; collaborative governance; forest management; monitoring; policy design; scale mismatch

\section{INTRODUCTION}

Since the 1970s, environmental governance scholars have emphasized the importance of embracing the complex, multiscalar nature of environmental management and, in particular, of addressing scalar mismatches to improve governance solutions (Imperial 1999, Cash and Moser 2000, Meadowcroft 2002, Cumming et al. 2006). Early literature focused on mismatches between the scales of management actions and ecological processes, while more recent literature has revealed a growing array of mismatches and other scale-related considerations, with insights from multiple disciplines (Gibson et al. 2000, Cash et al. 2006, Guerrero et al. 2013).

Addressing scale mismatches is an important aspect of adaptive governance, a mode of environmental governance that "allows emergence of collective action capable of facilitating adaptation to change and surprise as well as the capacity to itself evolve" (Cosens et al. 2018). The literature has highlighted candidate legal and institutional design principles to support adaptive governance and a need to investigate how these manifest as policy tools in specific contexts (Huitema et al. 2009, Cosens et al. 2017, DeCaro et al. 2017). Scholars have also noted the utility of bridging activities and boundary work to support cross-level and cross-scale arrangements that augment capacity to address scale mismatches by conferring flexibility, improving communication across governance levels and epistemic communities, and supporting collective action across state and nonstate actors (Cash et al. 2006, Folke et al. 2007, Termeer et al. 2010). A next frontier lies in understanding how to design specific policy tools that incorporate these features within specific legal and administrative contexts and across different arenas of environmental governance.
In this Insight paper, our goal is to contribute to the dialogue on policy design specifically to address scale mismatches. We reflect on our collective research on U.S. forest governance to synthesize what we have learned in studying recent policy changes that incorporate both specific tools to address issues of scale mismatch and adaptive governance policy design principles more broadly. We begin with a review of the range of scale-related challenges and their implications for governance, situating this discussion in the context of U.S. forest management. We then discuss findings from our research, focusing on two areas of policy change, collaborative forest restoration and multilevel monitoring, each of which is defined by significant and unique scale-related challenges. For each topic, we discuss how scale-related issues typically manifest. We then consider how policies are incorporating strategies to address scale mismatches and what our research reveals about these policy tools' effects. We conclude with a discussion of policy tools to address scale mismatches and suggest future research directions.

\section{SCALE CONSTRUCTS AND MISMATCHES}

Scale is "a heuristic employed by scientists and managers to organize their understanding of the world and the relationships and interactions therein" (Cash and Moser 2000:110). There is a distinction between scale as a construct, e.g., biogeophysical scale, and levels as units of analysis or positions within a scale, e.g., patches, landscapes, regions, globe (Gibson et al. 2000). In this paper, we discuss biogeophysical scale and spatial levels at which ecological processes occur within this scale. We also discuss the scales and levels at which governance institutions and organizations exist, whether this is related to jurisdiction, levels of hierarchy within a public organization, or the scope and extent of social networks involved in governance. Also of relevance are

${ }^{1}$ Department of Forest and Rangeland Stewardship, Colorado State University, Fort Collins, CO, USA, ${ }^{2}$ Ecosystem Workforce Program, Institute for a Sustainable Environment, University of Oregon, Eugene, OR, USA 
matters of temporal scale, referring to processes that occur and repeat over different lengths of time, e.g., political election cycles versus forest disturbance processes.

Ecologists emphasize the importance of planning at larger spatial extents than what has been typical, primarily to address perceived scalar mismatches, which occur when the scale of ecological processes fails to align with the scales of governance institutions, management actions, and demands for ecosystem services (Cumming et al. 2006). Lindenmayer (2008) offers a compendium of ecological variables, including species assemblages and disturbance regimes, to consider when identifying the geographical extent at which to approach conservation planning in land management. The challenge lies in the fact that there are always multiple ecological variables of interest that might drive management choices. For example, forest managers may be simultaneously managing for fire regimes at one spatial level and conservation of a species' habitat at another level, which might be much smaller or spatially distinct. This necessitates a multilevel approach and recognition that there is no single "right" spatial extent for matching governance institutions to the ecological system (Cash et al. 2006, Folke et al. 2007).

Multiple social science disciplines also have explored environmental scale constructs and their implications for governance (Gibson et al. 2000). The construction of scale is a common discursive strategy in environmental politics (Meadowcroft 2002). Schattschneider's (1960) foundational work on this issue described how actors could expand or contain conflict to achieve their political goals. For instance, during the forest management crises of the 1990s in the Pacific Northwest region of the United States and in British Columbia, environmental activists used scale framing as a primary strategy to achieve their political goals, casting forest conservation issues as being of national or international importance to draw in larger audiences (Pralle 2006). Scholars in geography emphasize that any "scalar narrative," which is a story about the relationships of people, places, and processes, has implications for governance (Sievanen et al. 2013). In all cases, scale constructs emerge from simultaneously interacting social and ecological variables, and the resulting choices about management approaches affect which resources are prioritized and which actors have power and legitimacy in affecting resource management (Cash et al. 2006, Campbell and Godfrey 2010). This is an important consideration on multiple-use landscapes, such as U.S. national forests, where the choice of management priorities and planning approaches depend on how and by whom goals are defined (Cortner and Moote 1999).

There are multiple types of scale-related challenges and mismatches, and each requires unique considerations and possible solutions (Table 1). Perhaps the most common problem is ignorance of cross-level dynamics, which manifests in the failure to recognize the aggregation of localized problems into larger spatial dynamics, or of short-term decisions into long-term problems (Cash et al. 2006). For example, in ways that were not wholly anticipated at the time, fire suppression at local levels significantly altered U.S. forest fire regimes over large spatial extents, leading to longer term effects that will require social and ecological adaptation to altered conditions (Schoennagel et al. 2017). As another example, analyses of cumulative effects to wildlife populations often have been inadequate because of ignorance of how effects from local management decisions accumulate over space and time (Schultz 2010).

The problem of ignorance is a result of and exacerbated by scale mismatches, most commonly the mismatch between the scales of management institutions and ecological processes, which hinders the achievement of management goals and limits learning from ecological feedbacks (Imperial 1999, Anderies et al. 2004, Cumming et al. 2006). In the United States and elsewhere, policy design and jurisdictional authority of administrative agencies contribute to a lack of alignment between the spatial extent at which actors are empowered to make decisions and those of ecological processes. Mismatches also occur between the scale of community-based organization to participate in land management with both the scale of federal land management institutions and the scale of ecological processes that stakeholder groups want to affect (Schultz et al. 2012). For achieving management objectives, such as climate change adaptation, that require the use of large-scale datasets, mismatches also can occur between the scale of assessment and that of decision making (Cash et al. 2006). Temporal scale mismatches also are prevalent in environmental governance. Challenges include overcoming the short-term thinking that results from annual budgeting, tenure of those in leadership positions, and political election cycles, in order to achieve long-term management goals, such as ecological restoration (Meadowcroft 2002, Biber 2009, 2013, DeLuca et al. 2010). These considerations all are relevant in the context of $U$. $\mathrm{S}$. forest governance and can include coordinating across jurisdictions to affect ecological processes like fire, or maintaining a coordinated program of work over time to support long-term goals like ecological restoration (Table 1).

\section{GOVERNANCE STRATEGIES TO ADDRESS SCALAR CHALLENGES}

The adaptive governance literature offers solutions generally to increase adaptive capacity and specifically to address scale-related challenges. For instance, to support adaptive governance, policies should be reflexive, allowing for iterative tailoring of general policy objectives to local contexts and self-organization; policies also should provide tangible support for activities and allow for participatory decision making, with clear rights for multiple actors to contribute to addressing social-ecological dilemmas (DeCaro et al. 2017). It is particularly important to balance stability at higher levels of the governance system with flexibility to adapt approaches to local contexts (Craig et al. 2017). This type of policy design is meant to increase adaptive capacity in the face of uncertainty and complexity. Specifically for addressing scale mismatches, it could create more opportunities to work across jurisdictions in ways that capitalize on local selforganization. A key question is how to build these kinds of structures into policy tools and embed them effectively in thick institutional contexts.

In terms of the structure of actors to address scale mismatches, scholars highlight the need for boundary work across epistemic communities and bridging work to connect actors across jurisdictions and facilitate collective action to work at spatial extents that can meaningfully affect ecological process (Cash et al. 2006, Folke et al. 2007). Networked and nested institutions also can balance the benefits of local, participatory governance 
Table 1. Types of scale challenges and examples from forest governance.

\begin{tabular}{ll}
\hline \hline Challenge (from Cash et al. 2006) & Possible Manifestations in Forest Governance \\
\hline Ignorance of scale-related issues & $\begin{array}{l}\text { Failure to recognize how short-term or local fire and forest management decisions aggregate over } \\
\text { space and time to affect long-term and large-scale disturbance dynamics (North et al. 2012, } \\
\text { Stephens et al. 2016). }\end{array}$ \\
& $\begin{array}{l}\text { Failure to recognize or adequately characterize the cumulative effects of dispersed management } \\
\text { actions on species populations (Schultz 2010). }\end{array}$ \\
$\begin{array}{l}\text { Mismatch between scale of management actions or } \\
\text { governance institutions and ecological problems }\end{array}$ & $\begin{array}{l}\text { Cheng 2017). } \\
\text { Cheordination across jurisdictions to affect watershed conditions (Huber-Stearns and }\end{array}$
\end{tabular}
governance institutions and ecological problems

Locally assessing species' habitat needs without an ability to plan for connectivity or conservation of multiple habitat types over species' life-stages (Schultz 2010).

Planning localized fuels treatments in a way that is unlikely to affect wildland fire behavior (North et al. 2012).

Failure to plan activities for different resource areas in a coordinated or integrated fashion, such that activities are not likely to complement each other effectively (Schultz et al. 2015).

Mismatch between scale of social organization with either scale of ecological problems of interest or scale at which management activities take place

Mismatch between scale of assessment and scale of information needed for decision making

Organizing locally around a municipality or watershed, but lacking ability to affect relevant ecological dynamics at larger scales that affect communities (Schultz et al. 2012).

Failure to organize in a way that matches how land management agencies organize, making it difficult to coordinate agreements or goals across actors and jurisdictions (Cyphers and Schultz 2019).

The tension between conducting climate change vulnerability assessments at regional scales with providing actionable suggestions or data that are useful for local managers (Cash et al. 2006, Timberlake and Schultz 2017).

Collecting monitoring data on multiple forests in different ways, making it difficult to aggregate data to inform decisions about large-scale ecological dynamics, e.g., for species with large ranges or to understand long-term vegetation dynamics (DeLuca et al. 2010, Schultz 2010, Wurtzebach and Schultz 2016).

Mismatch between ecological, political, and other Failure to invest in activities and associated monitoring efforts that require multiyear investments, decision-making timeframes which can be difficult because of annual appropriations cycles, or that do not yield measurable outcomes during time in office or position (Biber 2009, 2013).

Lack of collective action to proactively address consequences that are distant in time or characterized by uncertainty as to when, where, and what extent they will occur, e.g., mitigation of carbon emissions to slow climate change or application of prescribed fire to mitigate future fire hazard (Underdal 2010).

with coordination across actors and capacity at higher levels (Lemos and Agrawal 2006, Folke et al. 2007, Chaffin et al. 2014). There also may exist scale-specific comparative advantages, or "unique knowledge, technical capacity, or functional specialization" at different levels (Cash and Moser 2000:116). Therefore, organization and action at different levels, with crosslevel connections, may be necessary to support collective action across actors to match activities to the spatial extent of ecological processes, confer the flexibility to address different types of environmental governance problems at different levels, and leverage diverse capacities to increase both capacity and flexibility generally.

Historically, stakeholders have found it challenging to build consensus among diverse stakeholders across multiple jurisdictions functioning at both different temporal and spatial scales to accomplish large-scale environmental management (Heikkila and Gerlak 2005). These challenges are compounded by diverse agency interests, cultures, and capacities (Kettl 2006, Lubell et al. 2010). Nonetheless, the utility of both horizontal and vertical linkages is evident in emerging approaches to U.S. forest management, where networks of collaborative groups work together to promote collective learning and coordinate across levels; groups at higher levels set strategic objectives, enhance communication, share knowledge, and provide problem solving for lower level groups, which in turn define operational rules of management tailored to specific contexts (Wyborn and Bixler 2013). An important area of study is how to create the agency capacity and policy support to promote such partnerships and networks across actors, a question that is important for our purposes, given the fact that these structures are important for addressing scale mismatches (Robinson et al. 2011).

\section{A BRIEF OVERVIEW OF U.S. FOREST GOVERNANCE}

We consider how scale mismatches are addressed in U.S. federal forest policy, thus necessitating some background on this topic. The U.S. Forest Service manages 193 million acres of publicly owned forestlands across 154 national forests and grasslands. The agency has had a multiple-use mandate since the 1960s that leaves considerable discretion to the agency to identify the balance of uses on any given national forest (Nie 2008). For most of the last 
half of the 20th century, the agency prioritized timber harvest over other activities, despite the mandate to also manage for wildlife, watersheds, soil conservation, and other objectives. It also engaged in suppression of wildland fires, a practice that, despite policy changes, continues to predominate today (Stephens et al. 2016). In 1969, the Congress passed the National Environmental Policy Act, which, for federal decision-making processes, requires environmental impact assessment and public involvement, e.g., scoping for public concerns before actions are planned and public comments on draft environmental impact assessments and project alternatives. In addition, the Congress passed the Endangered Species Act in 1973 and the National Forest Management Act in 1976 (NFMA). The requirements of these policies require a greater consideration of wildlife conservation on national forests (Schultz et al. 2013), which, along with other factors, led to a decline in timber production on national forest lands in the early 1990s (Wear and Murray 2004).

In response to this reality and broader changes in policy tool preferences in the United States, new forest governance approaches began to emerge several decades ago (Sousa and Klyza 2007). In the 1990s, U.S. federal forest governance began to emphasize ecosystem management, which involved "a shift away from managing individual resources to the broader perspective of ecosystems and the use of collaborative decision making ..."(Imperial 1999:449). However, while ecosystem-based management and collaboration emerged as prominent aspects of forest management, the underlying laws that set requirements for endangered species protection, environmental impact analysis, and land management planning on national forests have remained unchanged since the 1970s. The federal forest governance system is still organized around a large federal bureaucracy that has formal decision-making authority on public lands. This leaves managers and stakeholders with the challenge of building approaches to adaptive governance into the interstitial spaces of existing legal and administrative frameworks (Sousa and Klyza 2007).

With regard to addressing scale mismatches and other challenges, the U.S. Forest Service and its partners have found ways to undertake cross-jurisdictional, adaptive planning within the context of existing statutes. The primary mandate for national forests today is the NFMA, which emphasizes multiple-use and requires the agency to develop land and resource management plans, or forest plans, which guide individual management actions, or projects, on national forests for a span of 10-15 years. Although forest planning is usually done at the forest level, it can be undertaken at levels beyond that of the individual unit. For example, the Northwest Forest Plan Record of Decision in 1994 amended the land management plans of 19 (now 17) national forests and seven Bureau of Land Management resource areas in the Northern Spotted Owl (Strix occidentalis caurina) range from the northern border of Washington to northern California (Spies et al. 2018). Agencies have also found ways to build some aspects of adaptive management into the environmental impact assessment process, per the requirements of the National Environmental Policy Act of 1969 (NEPA), although this is challenging and requires creativity, particularly in order to ensure accountability over time and compliance with legal requirements (Ruhl and Fischman 2010, Schultz and Nie 2012).
Today, forest governance in the United States and around the world is increasingly focused on "landscape" approaches, which bring together multiple stakeholder and epistemic communities to work on forest management in a way that is more scale-sensitive and cross-sectoral (Arts et al. 2017). Two prominent areas of emphasis in forest governance that require thinking at larger spatial extents are collaborative forest restoration and planning for ecological integrity. In the sections that follow, we draw upon findings from our recent research on policy changes in these two arenas to discuss policy tools to address scale-related challenges.

\section{EMERGING POLICY TOOLS AND APPROACHES TO SCALE MISMATCHES}

We take a deeper dive to look at some of the scale mismatches and challenges in two areas of U.S. forest governance: collaborative forest restoration and multilevel monitoring for ecological integrity. For each topic, we consider scale-related challenges, policy approaches to address these issues, and findings from our work on the effects of policy changes, along with other lessons learned. The details of our research design and methods can be found in other of our published empirical research papers that we cite throughout these sections. This section draws together insights from these publications to consider how policy tools can be designed to address scale mismatches.

\section{Policy tools to support collaborative forest restoration}

Forest restoration efforts, often designed to restore natural ecological processes such as fire, necessitate planning at a spatial extent large enough to affect ecological processes; also important is overcoming temporal scale mismatches to plan, implement, and monitor sequential actions to accomplish restoration goals through a process of adaptive management (DeLuca et al. 2010, North et al. 2012). Comanagement with community-based groups has become prevalent in U.S. forest restoration (Moseley and Winkel 2013). Groups provide expertise, resources, and an oftneeded social license to proceed with restoration at an increased pace and scale, relative to the recent past (Schultz et al. 2012, Abrams et al. 2017, Maier and Abrams 2018). In this arena, longstanding challenges have included failures to honor collaboratively forged agreements, plan activities that were strategically coordinated across landscapes to affect ecological processes, and maintain investments in project monitoring (Schultz et al. 2012, Biber 2013). Other challenges have included planning integrated projects across resource areas, e.g., including wildlife and watershed conservation activities, addressing invasive species, and conducting vegetation management and timber removal in the same projects; the result is that people working in different resource areas might not coordinate their activities, leading to another manifestation of the mismatch between ecological scales and those of management activities (Schultz et al. 2015, 2016). New policies have emerged largely in response to lobbying by community-based forestry organizations for policy changes that would facilitate enduring collaboration between the U.S. Forest Service and stakeholders, accelerate coordinated restoration activities in priority landscapes, and incorporate restoration activities across multiple resource areas (Schultz et al. 2012, USFS 2015). We consider here the design of several of these policy tools and lessons drawn from our research (see Table 2 for a summary of policies discussed in this paper). 
Table 2. Policy tools, objectives, design, and key findings related to scale mismatches.

\begin{tabular}{|c|c|}
\hline Policy Tool and Objective & Policy Design Aspects \\
\hline $\begin{array}{l}\text { The Collaborative Forest Landscape } \\
\text { Restoration Program, established by } \\
\text { law (P.L. 11-111) in } 2009 \text { to } \\
\text { "encourage the collaborative, } \\
\text { science-based ecosystem restoration } \\
\text { of priority forest landscapes" (16 U. } \\
\text { S.C. 7301). }\end{array}$ & $\begin{array}{l}\text { Up to } \$ 40 \text { million annually to be allocated to } \\
\text { priority forest landscapes based on proposals that } \\
\text { are collaboratively written by the U.S. Forest Service } \\
\text { and stakeholders. Projects must be }>20,000 \text { hectares } \\
\text { and articulate a landscape strategy based on } \\
\text { ecological, economic, and social variables. Projects } \\
\text { are selected by the Secretary of Agriculture with } \\
\text { input for a federal advisory committee, made up of } \\
\text { diverse stakeholders. Collaborators must be involved } \\
\text { in all aspects of the project, from proposal writing, } \\
\text { through planning, implementation, and monitoring. } \\
\text { Funding can be used for project implementation } \\
\text { and monitoring and is supposed to be for } 10 \text { years } \\
\text { (Congress has appropriated funding for projects } \\
\text { every year to date). The } 2018 \text { Farm Bill extended the } \\
\text { funding authorization under the CFLRP to } \$ 80 \\
\text { million annually until } 2023 \text {. }\end{array}$ \\
\hline $\begin{array}{l}\text { Joint Chiefs Landscape Restoration } \\
\text { Partnership, an interagency } \\
\text { initiative to support fire risk } \\
\text { reduction, wildlife habitat } \\
\text { improvement, and watershed } \\
\text { condition improvement on } \\
\text { forestlands across the public-private } \\
\text { boundary }\end{array}$ & $\begin{array}{l}\text { Focused funding for up to three years for projects } \\
\text { across public and private forestlands, based on } \\
\text { collaborative proposals from the U.S. Forest Service } \\
\text { and Natural Resource Conservation Service, which } \\
\text { works with private landowners. Projects must focus } \\
\text { on a landscape with the intention of reducing fire } \\
\text { risk, improving watershed conditions, or improving } \\
\text { wildlife habitat. }\end{array}$ \\
\hline
\end{tabular}

The Integrated Resource Restoration budget pilot, which was meant to improve prioritization, integration, and efficiency associated with planning and implementing restoration projects on national forests

\section{Key Findings}

Interviewees reported that they undertook larger scale plans, improving the fit of planning scales with those of ecological processes. They also reported innovative approaches to planning and communication, and more monitoring, which has been a challenge to maintain over time (Schultz et al. 2014, 2017, 2018). Requirements to collaborate with stakeholders, along with multiyear funding investments focused on a particular landscape, leveraged capacity and allowed for accelerated work over multiple years and at more contiguous spatial extents (Schultz et al. 2018).

Collaborators were able to bridge across the tenure of individual agency personnel, addressing temporal mismatches that often emerge from agency personnel management processes.

Collaboration requirements and funding focused on a particular landscape facilitated both better interagency coordination and private landowner engagement, resulting in more contiguous planning across jurisdictions, addressing mismatches between the scales of management activities, jurisdictions, and ecological processes (Cyphers and Schultz 2019). Collaborative requirements, along with multiyear funding investments, leveraged capacity, e.g., human resources and diverse knowledge/skills, to conduct work over multiple years on the focal landscape.

Multiple budget line-items, e.g., funding specifically About half of agency decision makers reported improved prioritization of specific landscapes and integration of activities, because staff members talked to each other more about collective priorities; some respondents also reported greater ease in planning multiyear activities and entering into multiyear contracts (Schultz et al. 2015, 2016). Findings indicate some alleviation of mismatches associated with temporal dissonance between long-term restoration planning and annual appropriations processes, as well as mismatches between the scales of planning, which were typically smaller and more single-resource focused, and those of target ecological processes.

The requirement has led to deliberation about the spatial extent at which different monitoring processes must be organized and available datasets for monitoring different resources and conditions, leading to consideration of scale mismatches in monitoring (Wurtzebach 2018). Research has revealed the need for new capacities to conduct monitoring, maintain monitoring programs over time, and translate findings across levels of the organization and among partners. Multiyear agreements to allocate funding with partners provide an opportunity to leverage capacity and overcome some of the tendencies to underfund monitoring, in part because of the mismatch between annual appropriation/evaluation cycles with the need to maintain monitoring investments over time.
One important policy change came in 2009, when the U.S. Congress passed a law establishing the Collaborative Forest Landscape Restoration Program, which has, as its primary objective, collaborative restoration of priority landscapes (CFLRP, P.L. 111-11). The program was innovative, i.e., it utilizes policy tools never heretofore implemented in U.S. forest management, in several ways, including the following: (1) it allocated funding through a competitive process to prioritize restoration projects with input from a multistakeholder federal advisory committee (whereas funding was typically allocated internally by the agency with no competitive or obvious prioritization processes); (2) it required projects to have in place a 10-year, landscape strategy to contextualize individually planned activities, which was a new requirement without prior analog; (3) it required involvement by collaborators at all stages of project progress, including in writing and submitting project 
proposals, as well as project planning, implementation, and monitoring (laws prior to this encourage collaboration in planning and monitoring but have never required collaboration for all phases of project implementation); (4) it authorized 10year funding commitments, which Congress has kept to date and which differ from typical annual appropriations processes; and (5) it allowed managers the flexibility to use appropriations for any of a variety of activities, e.g., fuels thinning, habitat restoration, or monitoring, which are typically funded out of separate line-item appropriations.

The policy incorporated a number of adaptive governance design principles, including tangible support for policy implementation, reflexivity, clearer rights for nonstate, local stakeholders, and a legal sunset. Some aspects of the policy were specific to addressing scale mismatches. The law included a minimum scale requirement, mandating that that a project's landscape strategy cover a minimum of 20,000 hectares, although the 23 CFLRP projects embraced much larger spatial extents, from approximately 50,000 and 1 million hectares. Proposals for investment had to present a landscape strategy for action based on ecological, social, and economic considerations. By using a competitive proposal process with multiyear funding commitments and requirements for collaboration, the policy was designed to focus investment by the Forest Service and stakeholders in a particular place for multiple years. It also allowed the flexible use of funds to support multiple activities, including monitoring, which typically falls by the wayside as a result of temporal mismatches and other variables like lack of capacity and incentives (Biber 2013).

Our research investigated whether this policy yielded the desired effects. We found that the combination of a landscape emphasis, multiyear funding commitment, and collaboration requirement proved to be a useful policy approach for addressing multiple scale-mismatches. Majorities of agency personnel reported that the policy supported landscape-scale planning, with coordinated work across different resource areas, e.g., habitat restoration and fuels reduction, addressing the common mismatch between scales of management activities and those of target ecological processes (Schultz et al. 2018). At the same time, projects were all different, demonstrating how the policy design allowed for tailoring projects to local needs and conditions. Some projects undertook environmental impact assessments at significantly larger scales than previously seen for vegetation management projects, and many built adaptive management into their planning, funding monitoring efforts at higher levels than in the past (Schultz et al. 2014, 2018). Thus, we saw some improvements with regard to the spatial extents of planning and also new opportunities to engage in longer term, iterative planning compared to the past. Although it was not true in all locations, on most projects, collaboration requirements and multiyear funding commitments supported collective action through improved collaborative relationships and leveraging of nonfederal capacity focused in a particular place; the landscape prioritization and funding commitments allowed for industry growth in some locations to support restoration work and facilitated multiparty monitoring efforts (Schultz et al. 2014, 2018). Such increased collective action can address scalar mismatches that result when communities organize at scales that are not aligned with those of target ecological process or those of agencies involved in land management. Staff capacity and leadership changes were major challenges, although stakeholders in some places created processes, including transition memos and annual on-boarding meetings, meant to bridge across the tenures of individual agency personnel and communicate collective goals and agreements, thus overcoming some persistent temporal scale-related challenges (Schultz et al. 2017).

Several other policies have been implemented with the intent of supporting collective action and planning for restoration at larger scales. A collaborative initiative between the Forest Service and the Natural Resource Conservation Service, called the Joint Chiefs Landscape Restoration Partnership, also used a competitive process and three-year funding commitments to incentivize coordinated restoration activities in a particular landscape but across jurisdictional boundaries (Cyphers and Schultz 2019). In most cases, the Joint Chiefs Partnership supported a more coordinated program of work across landscapes and jurisdictions, greater interagency coordination, and more landowner participation in agency-led projects, compared to business as usual (Schultz et al. 2018, Cyphers and Schultz 2019). Here too, we saw evidence of an example of a policy designed specifically to address scale mismatches, e.g., working on fire risk reduction or habitat improvement solely on public lands without coordination with private landowners, and of improvements with regard to temporal and spatial contiguity of planning.

As another example, the Integrated Resource Restoration (IRR) budget pilot, which came from a change in appropriations structure from Congress, combined separate budget line items into a single restoration line-item to increase flexibility, prioritization, and integration of planning across resource areas on several regions of the National Forest System. The funding flexibility under the IRR allowed some forests to plan at larger scales, enter into multiyear contracts with greater ease because they were less worried about having the right "color" of money to undertake activities in out years, and undertake a more integrated approach to planning across resource areas (Schultz et al. 2015, 2016). Land managers working with both the IRR and the CFLRP found the budgetary flexibility supportive of multiyear, landscape planning (Schultz et al. 2015).

Networks and partnerships played a significant role in project success under both the CFLRP and the Joint Chiefs approaches. Under the CFLRP, partnerships between science providers and collaborative stakeholder groups helped to develop monitoring approaches and support deliberation about restoration goals (Butler et al. 2015, Colavito 2017, Schultz et al. 2017, Urgenson et al. 2017). Multiple CFLRP groups also engaged in networking through regional and national groups to support collective learning, often to discuss common barriers and identify potential solutions (Schultz et al. 2017). For the Joint Chiefs Partnerships, collaborative stakeholder groups and key partners, e.g., community leaders or local nongovernmental organizations, served as a bridge between the two federal agencies involved, and between federal land managers and private forest landowners (Cyphers and Schultz 2019).

Our research on these policies reveals the potential for policy changes to influence the spatial and temporal extents of planning and action. Nonetheless, there were indications that these policy tools also led to significant trade-offs and only worked in some 
places. Prioritized investment for landscape work meant other locations and resource areas got less investment; some said that this could lead to systematic dysfunction on some units or for resources that do not benefit from landscape-focused approaches (Schultz et al. 2015). In addition, some places were more successful under these programs than others, often depending on the local history of collaboration, local buy-in, and local capacity (Schultz et al. 2018). Other agency-related factors, including lack of capacity, cumbersome agency processes, and poor leadership compromised project success in some places. Agency performance measures played a significant role in driving where work was occurring; for instance, targets to achieve timber outputs sometimes incentivized staff to prioritize landscapes that could yield timber volume but might be a lower priority for restoration. In other words, while these policies created space for overcoming scale challenges, there were some trade-offs and limitations, based on other agency institutions and other local dynamics.

Policies requiring multilevel monitoring for ecological integrity

Restoration supports management for ecological integrity, a broad goal of contemporary national forest management (see the NFMA regulations, revised in 2012 and at 36 CFR 219 et seq.). A central aspect of ecological integrity is developing multilevel monitoring strategies to track conditions and assess the impacts of management actions (Wurtzebach and Schultz 2016). Monitoring conducted over a variety of spatial and temporal scales is essential for the following: evaluating the effectiveness of management actions and measuring progress toward conservation goals (Nichols and Williams 2006, Deluca et al. 2010); providing early warnings of "state shifts" in ecosystem dynamics (Groffman et al. 2006); tracking species populations and distributions (Heller and Zavaleta 2009); and evaluating trends in landscape patterns and processes at ecoregional scales (Hutto and Belote 2013, Potter et al. 2016). However, there are often significant institutional barriers for the generation, transmission, and use of robust monitoring information, particularly in public land management agencies. Scalar challenges are endemic and addressing them requires new approaches and partnerships. Agency staff often lack expertise needed to design monitoring strategies that can generate credible and relevant information at appropriate temporal and spatial scales, necessitating the engagement of partners (Nichols and Williams 2006, Lindenmayer and Likens 2010). Budget cuts, turnover, information technology issues, decentralized decisionmaking structures, and problematic incentives complicate consistency and coordination for data collection and analysis (Doremus 2008, Biber 2013). In addition, mismatches between the spatial scales of monitoring and decision making, and problematic communication strategies often complicate the use of monitoring information in planning and decision-making contexts (Groffman et al. 2006, Bennetts et al. 2007).

In recognition of these challenges, multiple public land management organizations in the United States and Canada have developed new policies designed to support and improve multiscale ecological monitoring, often using the concept of ecological integrity to structure program implementation (Wurtzebach and Schultz 2016). Ecological integrity provides a framework for identifying key attributes of ecological systems essential for resilience, conserving biodiversity at different scales of ecological organization, and evaluating trends and progress toward meeting goals through quantitative benchmarks. Overcoming ignorance of the interactions between trends and conditions operating at different scales is a primary goal. Emerging strategies for supporting multilevel monitoring design, implementation, and communication are evident in the U.S. Forest Service's 2012 NFMA regulations, which require forests to identify and monitor key characteristics of ecological integrity at the national forest level and also direct each of the nine Forest Service Regions to develop "broader scale" monitoring strategies in collaboration with partner organizations for "plan monitoring questions that can best be answered at a geographic scale broader than one plan area" (36 CFR 219.12).

"Broader scale" monitoring implementation is in its early stages, but legal requirements have compelled staff within the Forest Service to deliberate about the scale at which particular management questions should be addressed and with what data sources, setting the stage for collective learning (Waltz et al. 2017). Agency staff perceived multiple opportunities and barriers associated with the broader scale monitoring requirements and highlighted the importance of collaboration and partnerships with other state, federal, research, and nongovernmental organizations that will allow the Forest Service to leverage capabilities and expertise for monitoring implementation that it does not have in-house (Wurtzebach 2018). To realize opportunities, staff indicated that multiyear funding agreements for partner monitoring developed at regional levels have the potential to mitigate temporal and spatial mismatches associated with budgetary cycles and jurisdictional boundaries by ensuring consistent data collection, data management, analysis, and communication across multiple units and fiscal years (Waltz et al. 2017).

Internal, agency dynamics will require attention to realize the potential of policy mandates for multilevel monitoring. Although coordinated monitoring at larger spatial scales might save money in the long run, it requires proof-of-concept to managers who are responsible for prioritizing funding and activities on their units, reorganization of existing practices, and persistence in the face of agency inertia or outright resistance to what might result in a decrease in field-level authority or financial resources (Waltz et al. 2017). In addition, assessing and evaluating the relevance of broader scale and long-term information is often difficult for staff whose day-to-day work is focused at smaller management scales (Waltz et al. 2017). Therefore, although staff may want to embrace the legal requirements, effective implementation will require funding and internal capacity to coordinate monitoring across resource and program areas, "translate" externally produced broader scale data so that it is relevant for end users, and provide technical assistance, accountability, and oversight for unit-level monitoring implementation (Wurtzebach 2018).

\section{IMPLICATIONS FOR POLICY DESIGN AND FUTURE RESEARCH}

We discuss observations based on our work, discuss connections to the adaptive governance literature, and offer some additional observations on the design of policy tools. For each of the different types of scale-related challenges and mismatches we discussed in the introduction to this paper (Cash et al. 2006, and see also Table 1), we offer some potential policy tools that could address each challenge based on our research (Table 3). For 
Table 3. Types of scale challenges and potential policy strategies.

\begin{tabular}{ll}
\hline \hline Challenge (from Cash et al. 2006) & Possible Policy Strategies Identified in Our Research \\
\hline Ignorance of scale-related issues & Policies that provide funding for or incentivize the convening of networks of scientists, managers, and \\
& stakeholders to identify how dynamics might aggregate across space and time (based on our findings on the \\
& Collaborative Forest Landscape Restoration Program (CFLRP) and Forest Service 2012 multilevel \\
& monitoring requirements; Schultz et al. 2018 and Wurtzebach 2018)
\end{tabular}

Requirements for data collection, assessment, and communication across actors and at multiple levels (as found with Forest Service 2012 multilevel monitoring requirements; Wurtzebach 2018).

Mismatch between scale of management Prioritization of funding for projects that explicitly address scale considerations across social, economic, and and ecological problem ecological variables (as found with the CFLRP and the Joint Chiefs Partnership; Schultz et al. 2018).

Requiring and incentivizing coordination across individual management units, agencies, or jurisdictions in order to receive funding (as found with the CFLRP and Joint Chiefs approaches; Cyphers and Schultz 2019).

Flexible, multiyear funding commitments to support a coordinated program of work over time in particular places (as found with the CFLRP, Joint Chiefs, and Integrated Resource Restoration (IRR) approaches; Schultz et al. 2015, 2018).

Mismatch between scale of social organization with either scale of management or ecological problem

Mismatch between scale of assessment and scale of information needed for decision making

Mismatch between ecological, political, and other decision-making timeframes
Requiring collaborative planning and implementation among community-based groups and land managers (as found with the CFLRP and Joint Chiefs approaches; Schultz et al. 2017).

Requiring groups to organize at a minimum spatial scale (as found with the CFLRP; Schultz et al. 2018).

Flexible, multiyear funding commitments to incentivize collective action across actors (as found with the CFLRP and Joint Chiefs approaches; Schultz et al. 2018).

Promoting, either through flexible funding, collaborative requirements, or other tools, science-management partnerships to bridge epistemic communities and address scale mismatches (based on findings on the CFLRP and multilevel monitoring requirements; Schultz et al. 2018 and Wurtzebach 2018).

Requirements (and commensurate investments) for multiscale monitoring approaches (based on research on multilevel monitoring approaches; Wurtzebach 2018).

Multiyear and flexible funding commitments to support work over multiple years (as found for the IRR, CFLRP, and Joint Chiefs approaches; Schultz et al. 2015, 2018)

Required collaboration among land managers and stakeholders to promote transmission of existing, collaboratively developed agreements and practices to incoming personnel in leadership positions (as found with the CFLRP; Schultz et al. 2018). instance, policies like the CFLRP and multilevel monitoring requirements under the NFMA regulations bring together diverse actors to deliberate about how to configure land management activities and monitoring to reduce ignorance of scale-related challenges and mismatches. Although we did not measure reductions in ignorance of scale-related dynamics, we observed greater deliberation on the scales of ecological processes and how to better align planning and monitoring approaches with the scales of ecological variables throughout our work looking at the effects of these policies (Schultz et al. 2018, Wurtzebach 2018). To address the mismatch between scales of social organization, management actions, and ecological processes, policies like the Joint Chiefs Partnership and CFLRP that mandate consideration of spatial scale and fund work across jurisdictions led to planning and implementation of work at larger spatial extents and greater collective action across jurisdictions (Schultz et al. 2018). When coupled with multiyear funding commitments, flexible funding streams, and prioritization processes via competitions for funding, these approaches supported larger scale and longer term planning and land management (Schultz et al. 2018). It is also worth noting that flexible funding streams, like that of the IRR, on some units led to larger scale and longer term planning without specific mandates to undertake such efforts (Schultz et al. 2015, 2016).
We also observed that requirements for collaboration in forest restoration efforts and multilevel monitoring led to some efforts to address the mismatch between information in assessments and decision making; for instance, Wurtzebach (2018) found that partners were actively engaging with this issue in response to new multilevel monitoring requirements. Other work by Timberlake and Schultz (2017) indicates that science-management partnerships are critical in this regard. And, although we did not investigate this for the CFLRP, work by Colavito (2017) and Urgenson et al. (2017) indicates that the collaborative aspects of the CFLRP were leading to new efforts to engage scientists in landscape planning efforts. Policy tools that either facilitate or require science-manager connections are likely to be useful for addressing mismatches (Cash et al. 2006); our work provides additional empirical support for this and examples of different types of policy tools to achieve this. We also found evidence that multiyear, flexible funding commitments, with collaborative partners in place to oppose some of the annual performance and appropriations dynamics within the federal government, are useful for overcoming temporal mismatches.

We offer these policy tools as potentially useful approaches for addressing scale mismatches. In particular, these may be useful for other contexts where large, public bureaucracies play a central 
role in land management, given that a number of these tools promote coordination across the public-private land boundary and state and nonstate actors in a system dominated by federal decision makers and appropriators. We also note that the effects of these tools must be tested over time and in other contexts, and we offer our findings here as initial propositions to set the stage for future research.

\section{Connections to design principles for adaptive governance}

It is worth considering in more detail how these approaches incorporated legal and institutional design principles for adaptive governance, in order to look at both how this supported scale sensitivity and how these design principles manifested in practice. The policies highlighted in this paper incorporate recommendations for reflexivity and a blend of stability and flexibility (Craig et al. 2017, DeCaro et al. 2017). Policies blended top-down mandates, with associated funding, that included general policy objectives and requirements to consider scale, with space for local flexibility to tailor proposals and implementation approaches in response to local self-organizations across diverse types of actors. For instance, the CFLRP mandated consideration of scale by requiring justification for restoration projects based on ecological processes, the spatial extent needed to engage industry and generate rural jobs, and the scale at which community-based groups were organized. At the same time, it provided considerable flexibility in identifying restoration priorities in specific places, the location and extent or planned activities, the relevant partners, and the mix of implemented actions. Similarly, broad-scale monitoring requirements put into place mandates to consider scale and find new partnerships but left the identification of priorities for monitoring and the identification of partnerships to regional and local land managers. We cannot say specifically that reflexivity was central to success, given that there is no other context to compare to where the many other aspects of these policy tools were implemented but with less flexibility to tailor approaches to local contexts. Nonetheless our work provides some circumstantial evidence that this approach to adaptive governance generally also supports scale sensitivity.

We also saw some additional evidence of the importance of networks, partnerships, and boundary work in overcoming scale mismatches. The important role of partners in acting in both bridging, i.e., building connections among diverse actors, and boundary, i.e., bringing together different epistemic communities, roles was a major finding in research on the CFLRP (Colavito 2017, Schultz et al. 2018). Under the Joint Chiefs Partnership, interviewees said community partners were important for facilitating community between the federal government and local citizens. For broader scale monitoring requirements, interviewees said partnerships with nongovernmental organizations would be essential to leveraging existing knowledge and capacity (Wurtzebach 2018). In essence, facilitating bridging and boundary work, as recommended by Cash et al. (2006), was another important aspect of overcoming scale mismatches that these policies both promoted, some with explicit collaboration requirements and others by creating a need to capitalize on the resources of multiple partners.

These policies also incorporated other legal and institutional design principles for adaptive governance. For instance, the CFLRP offered tangible support and clearer rights for nonstate actors. These policies and their implementation all relied on improved partnerships through collaboration with science partners and diverse stakeholders, allowing for the collective action and participatory decision making that the scholarship argues is central to successful adaptive governance. The CFLRP also was a 10 -year pilot with a legislated sunset. What was missing in these policies was often the full complement of tangible support needed for successful policy implementation, something that many interviewees highlighted as problematic (Schultz et al. 2018, Wurtzebach 2018, Cyphers and Schultz 2019).

Our observation is that these design principles supported scale sensitivity and improved scale-matching, while also supporting other normative goals of adaptive governance, including collective action. This indicates there is complementarity among the adaptive governance design principles for achieving multiple, desired governance outcomes that should increase adaptive capacity (DeCaro et al. 2017). A challenge lies in continuing to assess in specific contexts whether variables like scale sensitivity and collection action result in a greater capacity to adapt to socialecological governance challenges and how this adaptiveness manifests in practice.

\section{Policy tool targets and mixes}

It is important to note that the policies highlighted in this paper utilize a complementary mix of policy tools to address scalar issues and achieve policy goals (Howlett 2004). Within the CFLRP, for example, mandates for collaboration and flexibility for local decision making were packaged with dedicated funding and incentives for participation. Indeed, our findings suggest that policies designed to promote multiscalar action require considerable financial and organizational support. New policies often require new structures, processes, and capacities to support successful implementation (Steelman 2010). For instance, investment in internal positions focused on knowledge brokering, particularly at middle management levels of an organization, may be particularly important for the generation, communication, and use of multilevel monitoring information, or for other multilevel needs in public organizations (Burgess and Currie 2013, Wurtzebach 2018). The research on restoration policies found that there is an increased need for focused capacity, coordinating positions, and strategies to stave off staff turnover and vacancies (Schultz et al. 2017). Supportive policy implementation mechanisms may also be needed to ease the development of boundary work and networking. For example, federal agencies could pursue funding mechanisms that allow for contracting with bridging organizations or organizational strategies that promote knowledge exchange through networking or learning forums. In essence, policy tools to support improved sensitivity to scalerelated challenges and mismatches may need to be packaged with a mix of administrative policy tools, such as novel staffing structures and budgeting processes. Adaptive governance may only be able to proceed as quickly as its slowest moving institutions, which, in places like the United States where public organizations play a dominant role in environmental governance, will be embedded in the structure, processes, and cultures of federal bureaucracies (Abrams et al. 2017). Therefore, identifying how these institutions interact with policy changes is central to supporting improved governance approaches in places where state-run bureaucracies play a dominant role. 
It is also critical to note that policy tools have to be tailored to specific contexts and policy targets (Howlett 2009). Multiple types of policy tools, including authority, incentive, and capacity tools all can be useful for promoting desired policy outcomes, but are most effective when they are customized for specific administrative and social contexts (Schneider and Ingram 1990). As such, we leave open the possibility that planning at larger scales or utilizing partnerships could be mandated, incentivized, or promoted through the use of a variety of policy tools, in addition to the specific tools we identified herein; it is also critical to note that policy tools will yield different results in various contexts and must be met with the necessary capacities, alongside numerous other factors, to have the intended effects in any given situation (Howlett 2009). Approaches like the CFLRP also will require new capacities for planning and collaboration among agency and stakeholder partners and, as we found, will meet with different success depending on local collaborative histories and capacity. Indeed, tailoring policy tools to specific settings often requires significant managerial and analytical expertise (Wu et al. 2015). A related challenge is policy integration, ensuring policy goals and tools are both well matched to specific contexts, and coherent across multiple levels of governance (Howlett et al. 2017). Policy tools designed to support flexible and adaptive decision making at local scales, for instance, may create challenges for coordination and long-term planning at higher levels of governance (Hill and Engle 2013).

\section{CONCLUSIONS}

Our work offers two primary contributions to the literature. First, we offer a look at specific policy tools that incorporate legal and institutional design principles for adaptive governance in a specific context. This has value in demonstrating specific applications of adaptive governance principles and expands the reach of the literature on policy design for adaptive governance, much of which recently has built on empirical work in water governance but which we find has applications in forest governance (Cosens et al. 2017, DeCaro et al. 2017). Second, we offer a compendium of tools that may be useful specifically for addressing scale mismatches, which is a specific concern raised repeatedly in the adaptive governance literature (Folke et al. 2007). Additional research could further explore these ideas in other contexts, build empirical evidence of how policies address scale mismatches, and examine how policies must be mixed to be effective in achieving this and other goals for improved environmental governance.

We conclude by highlighting challenges attendant to these policy changes that would benefit from additional attention and research, in addition to the points we have raised about considering the capacities and mixes of policy tools needed to successfully address scale mismatches. More flexible approaches raise questions about accountability to political overseers and to stakeholders, and may require additional oversight and evaluation strategies; in addition, more attention is needed to address the challenge of measuring and communicating results of long-term endeavors like restoration at multiple time steps (Schultz et al. 2015). It also is critical to consider how to support ongoing, high-priority work at different spatial levels. Working across larger landscapes may not be effective for resources that benefit from attention at smaller spatial levels. Coordinated monitoring at larger spatial extents may improve scientific utility but compromise management relevance of data collection (Wurtzebach and Schultz 2016). Another critical area for future research will be to investigate the drivers and impacts of scale constructs for actors and resources. This is a theme in the broader literature (e.g., Sievanen et al. 2013) that has not been extensively explored in U.S. land management. This kind of research on choices about scale would yield insights about various trade-offs and advantages.

Responses to this article can be read online at: http://www.ecologyandsociety.org/issues/responses. php/10703

\begin{abstract}
Acknowledgments:
Research referenced herein was funded through agreements 13CS-11132420-254, 14-DG-11031600-082, and 16-CS-11132000-272 with the USDA Forest Service. This material also is based upon work supported by the National Science Foundation under Grant No. 1702676.
\end{abstract}

\section{LITERATURE CITED}

Abrams, J. B., H. R. Huber-Stearns, C. Bone, C. A. Grummon, and C. Moseley. 2017. Adaptation to a landscape-scale mountain pine beetle epidemic in the era of networked governance: the enduring importance of bureaucratic institutions. Ecology and Society 22(4):22. http://dx.doi.org/10.5751/ES-09717-220422

Anderies, J. M., M. A. Janssen, and E. Ostrom. 2004. A framework to analyze the robustness of social-ecological systems from an institutional perspective. Ecology and Society 9(1):18. http://dx. doi.org/10.5751/ES-00610-090118

Arts, B., M. Buizer, L. Horlings, V. Ingram, C. van Oosten, and P. Opdam. 2017. Landscape approaches: a state-of-the-art review. Annual Review of Environment and Resources 42:439-463. http:// dx.doi.org/10.1146/annurev-environ-102016-060932

Bennetts, R. E., J. E. Gross, K. Cahill, C. McIntyre, B. B. Bingham, A. Hubbard, L. Cameron, and S. L. Carter. 2007. Linking monitoring to management and planning: assessment points as a generalized approach. George Wright Forum 24:59-77.

Biber, E. 2009. Too many things to do: how to deal with the dysfunctions of multiple-goal agencies? Harvard Environmental Law Review 33:1-63.

Biber, E. 2013. The challenge of collecting and using environmental monitoring data. Ecology and Society 18(4):68. http://dx.doi.org/10.5751/ES-06117-180468

Burgess, N., and G. Currie. 2013. The knowledge brokering role of the hybrid middle level manager: the case of healthcare. British Journal of Management 24(S1):S132-S142. http://dx.doi. org/10.1111/1467-8551.12028

Butler, W. H., A. Monroe, and S. McCaffrey. 2015. Collaborative implementation for ecological restoration on U.S. public lands: implications for legal context, accountability, and adaptive management. Environmental Management 55:564-577. http://dx. doi.org/10.1007/s00267-014-0430-8 
Campbell, L. M., and M. H. Godfrey. 2010. Geo-political genetics: claiming the commons through species mapping. Geoforum 41:897-907. http://dx.doi.org/10.1016/j.geoforum.2010.06.003

Cash, D. W., W. N. Adger, F. Berkes, P. Garden, L. Lebel, P. Olsson, L. Pritchard, and O. Young. 2006. Scale and cross-scale dynamics: governance and information in a multilevel world. Ecology and Society 11(2):8. http://dx.doi.org/10.5751/ES-01759-110208

Cash, D. W., and S. C. Moser. 2000. Linking global and local scales: designing dynamic assessment and management processes. Global Environmental Change 10:109-120. http://dx.doi. org/10.1016/S0959-3780(00)00017-0

Chaffin, B. C., H. Gosnell, and B. A. Cosens. 2014. A decade of adaptive governance scholarship: synthesis and future directions. Ecology and Society 19(3):56. http://dx.doi.org/10.5751/ ES-06824-190356

Colavito, M. M. 2017. The role of science in the Collaborative Forest Landscape Restoration Program. Journal of Forestry 115:34-42. http://dx.doi.org/10.5849/jof.15-142

Cortner, H. J., and M. A. Moote. 1999. The politics of ecosystem management. Island, Washington, D.C., USA.

Cosens, B. A., R. K. Craig, S. Hirsch, C. A. (T.) Arnold, M. H. Benson, D. A. DeCaro, A. S. Garmestani, H. Gosnell, J. Ruhl, and E. Schlager. 2017. The role of law in adaptive governance. Ecology and Society 22(1):30. http://dx.doi.org/10.5751/ ES-08731-220130

Cosens, B. A., L. Gunderson, and B. C. Chaffin. 2018. Introduction to the Special Feature Practicing Panarchy: assessing legal flexibility, ecological resilience, and adaptive governance in regional water systems experiencing rapid environmental change. Ecology and Society 23(1):4. http://dx. doi. org/10.5751/ES-09524-230104

Craig, R. K., A. S. Garmestani, C. R. Allen, C. A. Arnold, H. Birgé, D. A. DeCaro, A. K. Fremier, H. Gosnell, and E. Schlager. 2017. Balancing stability and flexibility in adaptive governance: an analysis of tools available in U.S. environmental law. Ecology and Society 22(2):3. http://dx.doi.org/10.5751/ES-08983-220203

Cumming, G. S., D. H. M. Cumming, and C. L. Redman. 2006. Scale mismatches in social-ecological systems: causes, consequences, and solutions. Ecology and Society 11(1):14. http:// dx.doi.org/10.5751/ES-01569-110114

Cyphers, L. A., and C. A. Schultz. 2019. Policy design to support cross-boundary land management: the example of the Joint Chiefs Landscape Restoration Partnership. Land Use Policy 80:362-369. http://dx.doi.org/10.1016/j.landusepol.2018.09.021

DeCaro, D. A., B. C. Chaffin, E. Schlager, A. S. Garmestani, and J. B. Ruhl. 2017. Legal and institutional foundations of adaptive environmental governance. Ecology and Society 22(1):32. http:// dx.doi.org/10.5751/ES-09036-220132

DeLuca, T. H., G. H. Aplet, B. Wilmer, and J. Burchfield. 2010. The unknown trajectory of forest restoration: a call for ecosystem monitoring. Journal of Forestry 108:288-295.

Doremus, H. 2008. Data gaps in natural resource management: sniffing for leaks along the information pipeline. Indiana Law Journal 83(2):407-463.
Folke, C., L. Pritchard, F. Berkes, J. Colding, and U. Svedin. 2007. The problem of fit between ecosystems and institutions: ten years later. Ecology and Society 12(1):30. http://dx.doi.org/10.5751/ ES-02064-120130

Gibson, C. C., E. Ostrom, and T. K. Ahn. 2000. The concept of scale and the human dimensions of global change: a survey. Ecological Economics 32:217-239. http://dx.doi.org/10.1016/ $\underline{\text { S0921-8009(99)00092-0 }}$

Groffman, P. M., J. S. Baron, T. Blett, A. J. Gold, I. Goodman, L. H. Gunderson, B. M. Levinson, M. A. Palmer, H. W. Paerl, G. D. Peterson, N. L. Poff, D. W. Rejeski, J. F. Reynolds, M. G. Turner, K. C. Weathers, and J. Wiens. 2006. Ecological thresholds: the key to successful environmental management or an important concept with no practical application? Ecosystems 9:1-13 http:// dx.doi.org/10.1007/s10021-003-0142-Z

Guerrero, A. M., R. R. J. McAllister, J. Corcoran, and K. A. Wilson. 2013. Scale mismatches, conservation planning, and the value of social-network analyses. Conservation Biology 27 (1):35-44. http://dx.doi.org/10.1111/j.1523-1739.2012.01964.x

Heikkila, T., and A. K. Gerlak. 2005. The formation of largescale collaborative resource management institutions: clarifying the roles of stakeholders, science, and institutions. Policy Studies Journal 33:583-612. http://dx.doi.org/10.1111/j.1541-0072.2005.00134. $\underline{\mathrm{X}}$

Heller, N. E., and E. S. Zavaleta. 2009. Biodiversity management in the face of climate change: a review of 22 years of recommendations. Biological Conservation 142(1):14-32. http:// dx.doi.org/10.1016/j.biocon.2008.10.006

Hill, M., and N. L. Engle. 2013. Adaptive capacity: tensions across scales. Environmental Policy and Governance 23(3):177-192. http:// dx.doi.org/10.1002/eet.1610

Howlett, M. 2004. Beyond good and evil in policy implementation: instrument mixes, implementation styles, and second-generation theories of policy instrument choice. Policy and Society 23(2):1-17. http://dx.doi.org/10.1016/S1449-4035(04) 70030-2

Howlett, M. 2009. Governance modes, policy regimes and operational plans: a multi-level nested model of policy instrument choice and policy design. Policy Sciences 42:73-89. http://dx.doi. org/10.1007/s11077-009-9079-1

Howlett, M., J. Vince, and P. Río. 2017. Policy integration and multi-level governance: dealing with the vertical dimension of policy mix designs. Politics and Governance 5(2):69-78. http://dx. doi.org/10.17645/pag.v5i2.928

Huber-Stearns, H. R., and A. S. Cheng. 2017. The evolving role of government in the adaptive governance of freshwater socialecological systems in the western U.S. Environmental Science and Policy 77:40-48. http://dx.doi.org/10.1016/j.envsci.2017.07.011

Huitema, D., E. Mostert, W. Egas, S. Moellenkamp, C. PahlWostl, and R. Yalcin. 2009. Adaptive water governance: assessing the institutional prescriptions of adaptive (co-)management from a governance perspective and defining a research agenda. Ecology and Society 14(1):26. http://dx.doi.org/10.5751/ES-02827-140126 
Hutto, R. L., and R. T. Belote. 2013. Distinguishing four types of monitoring based on the questions they address. Forest Ecology and Management 289:183-189. http://dx.doi.org/10.1016/j. foreco.2012.10.005

Imperial, M. T. 1999. Institutional analysis and ecosystem-based management: the institutional analysis and development framework. Environmental Management 24(4):449-465. http://dx. doi.org/10.1007/s002679900246

Kettl, D. F. 2006. Managing boundaries in American administration: the collaboration imperative. Public Administration Review 66:10-19. http://dx.doi.org/10.1111/j.1540-6210.2006.00662. $\underline{\mathrm{x}}$

Lemos, M. C., and A. Agrawal. 2006. Environmental governance. Annual Review of Environmental Resources 31:297-325. http://dx. doi.org/10.1146/annurev.energy.31.042605.135621

Lindenmayer, D. 2008. A checklist for ecological management of landscapes for conservation. Ecology Letters 11:78-91.

Lindenmayer, D. B., and G. E. Likens. 2010. The science and application of ecological monitoring. Biological Conservation 143 (6):1317-1328. http://dx.doi.org/10.1016/j.biocon.2010.02.013

Lubell, M., A. D. Henry, and M. McCoy. 2010. Collaborative institutions in an ecology of games. American Journal of Political Science 54(2):287-300. http://dx.doi.org/10.1111/j.1540-5907.2010.00431. $\underline{\mathrm{x}}$

Maier, C., and J. B. Abrams. 2018. Navigating social forestry a street-level perspective on national forest management in the $\mathrm{U}$. S. Pacific Northwest. Land Use Policy 70:432-441. http://dx.doi. org/10.1016/j.landusepol.2017.11.031

Meadowcroft, J. 2002. Politics and scale: some implications for environmental governance. Landscape and Urban Planning 61:169-179. http://dx.doi.org/10.1016/S0169-2046(02)00111-1

Moseley, C., and G. Winkel. 2013. Sustainable forest management on federal lands in the U.S. Pacific Northwest: making sense of science, conflict, and collaboration. Pages 189-203 in P. Katila, G. Galloway, W. de Jong, P. Pacheco, and G. Mery, editors. Forests under pressure: local solutions to global issues. International Union of Forest Research Organizations, Vienna, Austria.

Nichols, J. D., and B. K. Williams. 2006. Monitoring for conservation. Trends in Ecology and Evolution 21(12):668-673. http://dx.doi.org/10.1016/j.tree.2006.08.007

Nie, M. 2008. The governance of western public lands: mapping its present and future. University Press of Kansas, Lawrence, Kansas, USA.

North, M., B. M. Collins, and S. Stephens. 2012. Using fire to increase the scale, benefits, and future maintenance of fuels treatments. Journal of Forestry 110:392-401. http://dx.doi. org/10.5849/jof.12-021

Potter, K. M., F. H. Koch, C. M. Oswalt, and B. V. Iannone III. 2016. Data, data everywhere: detecting spatial patterns in finescale ecological information collected across a continent. Landscape Ecology 31:67-84. http://dx.doi.org/10.1007/s10980-015-0295-0

Pralle, S. B. 2006. Branching out, digging in: environmental advocacy and agenda setting. Georgetown University Press, Washington, D.C., USA.
Robinson, C. J., R. D. Margerum, T. M. Koontz, C. Moseley, and S. Lurie. 2011. Policy-level collaboratives for environmental management at the regional scale: lessons and challenges from Australia and the United States. Society and Natural Resources 24:849-859. http://dx.doi.org/10.1080/08941920.2010.487848

Ruhl, J. B., and R. L. Fischman. 2010. Adaptive management in the courts. Minnesota Law Review 95:424-484.

Schattschneider, E. E. 1960. The semi-sovereign people. Holt, Rinehart and Winston, New York, New York, USA.

Schneider, A., and H. Ingram. 1990. Behavioral assumptions of policy tools. Journal of Politics 52(2):510-529. http://dx.doi. org/10.2307/2131904

Schoennagel, T., J. K. Balch, H. Brenkert-Smith, P. E. Dennison, B. J. Harvey, M. A. Krawchuk, N. Mietkiewicz, P. Morgan, M. A. Moritz, R. Rasker, M. G. Turner, and C. Whitlock. 2017. Adapt to more wildfire in western North American forests as climate changes. Proceedings of the National Academy of Sciences 114 (18):4582-4590. http://dx.doi.org/10.1073/pnas.1617464114

Schultz, C. 2010. Challenges in connecting cumulative effects analysis to effective wildlife conservation planning. BioScience 60 (7):545-551. http://dx.doi.org/10.1525/bio.2010.60.7.10

Schultz, C. A., D. L. Coelho, and R. D. Beam. 2014. Design and governance of multiparty monitoring under the USDA Forest Service's Collaborative Forest Landscape Restoration Program. Journal of Forestry 112:198-206. http://dx.doi.org/10.5849/ jof.13-070

Schultz, C. A., T. Jedd, and R. D. Beam. 2012. The Collaborative Forest Landscape Restoration Program: a history and overview of the first projects. Journal of Forestry 110(7):381-391. http://dx. doi.org/10.5849/jof.11-082

Schultz, C. A., K. M. Mattor, and C. Moseley. 2016. Aligning policies to support forest restoration and promote organizational change. Forest Policy and Economics 73:195-203. http://dx.doi. org/10.1016/j.forpol.2016.09.015

Schultz, C. A., K. B. McIntyre, L. Cyphers, A. Ellison, C. Kooistra, and C. Moseley. 2017. Strategies for success under Forest Service restoration initiatives. Ecosystem Workforce Program Institute for a Sustainable Environment, University of Oregon, Eugene, Oregon, USA. [online] URL: https://scholarsbank. uoregon.edu/xmlui/handle/1794/22980

Schultz, C. A., K. B. McIntyre, L. Cyphers, C. Kooistra, A. Ellison, and C. Moseley. 2018. Policy design to support forest restoration: the value of focused investment and collaboration. Forests 9(9):512. http://dx.doi.org/10.3390/f9090512

Schultz, C. A., C. Moseley, and K. Mattor. 2015. Striking the balance between budgetary discretion and performance accountability: the case of the U.S. Forest Service's approach to integrated restoration. Journal of Natural Resources Policy Research 7(2-3):109-123. http://dx.doi.org/10.1080/19390459.20$\underline{15.1027533}$

Schultz, C., and M. Nie. 2012. Decision making triggers, adaptive management, and natural resources law and planning. Natural Resources Journal 52:443-521. 
Schultz, C. A., T. D. Sisk, B. R. Noon, and M. A. Nie. 2013. Wildlife conservation planning under the United States Forest Service's 2012 planning rule. Journal of Wildlife Management 77 (3):428-444. http://dx.doi.org/10.1002/jwmg.513

Sievanen, L., R. L. Gruby, and L. M. Campbell. 2013. Fixing marine governance in Fiji? The new scalar narrative of ecosystembased management. Global Environmental Change 23:206-216. http://dx.doi.org/10.1016/j.gloenvcha.2012.10.004

Sousa, D. J., and C. M. Klyza. 2007. New directions in environmental policy making: an emerging collaborative regime or reinventing interest group liberalism? Natural Resources Journal 47:378-444.

Spies, T. A., P. A. Stein, R. Gravenmier, J. W. Long, and M. J. Reilly. 2018. Synthesis of science to inform landmanagement within the Northwest Forest Plan Area. General Technical Report PNWGTR-966. U.S. Forest Service, Pacific Northwest Research Station, Portland, Oregon, USA.

Steelman, T. 2010. Implementing innovation. Georgetown University Press, Washington, D.C., USA.

Stephens, S. L., B. M. Collins, E. Biber, and P. Z. Fulé. 2016. U. S. federal fire and forest policy: emphasizing resilience in dry forests. Ecosphere 7(11):e01584. http://dx.doi.org/10.1002/ ecs2.1584

Termeer, C. J. A. M., A. Dewulf, and M. van Lieshout. 2010. Disentangling scale approaches in governance research: comparing monocentric, multilevel, and adaptive governance. Ecology and Society 15(4):29. http://dx.doi.org/10.5751/ ES-03798-150429

Timberlake, T. J., and C. A. Schultz. 2017. Policy, practice, and partnerships for climate change adaptation on U.S. national forests. Climatic Change 144(2):257-269. http://dx.doi.org/10.1007/ $\underline{\text { s10584-017-2031-Z }}$

Underdal, A. 2010. Complexity and challenges of long-term environmental governance. Global Environmental Change 20:386-393. http://dx.doi.org/10.1016/j.gloenvcha.2010.02.005

Urgenson, L. S., C. M. Ryan, C. B. Halpern, J. D. Bakker, R. T. Belote, J. F. Franklin, R. D. Haugo, C. R. Nelson, and A. E. M. Waltz. 2017. Visions of restoration in fire-adapted forest landscapes: lessons from the Collaborative Forest Landscape Restoration Program. Environmental Management 59:338-353. http://dx.doi.org/10.1007/s00267-016-0791-2

U.S. Forest Service. 2015. From accelerating restoration to creating and maintaining resilient landscapes and communities across the nation: update on progress from 2012. FS-1069. U.S. Department of Agriculture, Washington, D.C., USA.

Waltz, A., Z. Wurtzebach, B. Esch, T. Wasserman, and C. Schultz. 2017. Developing a framework for the U.S. Forest Service broaderscale monitoring strategy: processes and outcomes. Technical Report. Northern Arizona University Ecological Restoration Institute, Flagstaff, Arizona, USA. [online] URL: http://sweri.eri. nau.edu/PDFs/BSMSStrategyReport 22317 with\%20appendices. pdf
Wear D. N., and B. C. Murray. 2004. Federal timber restrictions, interregional spillovers, and the impact on U.S. softwood markets. Journal of Environmental Economics and Management 47:307-330. http://dx.doi.org/10.1016/S0095-0696(03)00081-0

Wu, X., M. Ramesh, and M. Howlett. 2015. Policy capacity: a conceptual framework for understanding policy competences and capabilities. Policy and Society 34(3-4):165-171. http://dx.doi. org/10.1016/j.polsoc.2015.09.001

Wurtzebach, Z. 2018. Knowledge management for adaptive planning and decision-making in federal land management agencies Dissertation. Colorado State University, Fort Collins, Colorado, USA.

Wurtzebach, Z., and C. Schultz. 2016. Measuring ecological integrity: history, practical application, and research opportunities. BioScience 66:446-457. http://dx.doi.org/10.1093/ biosci/biw037

Wyborn, C., and R. P. Bixler. 2013. Collaboration and nested environmental governance: scale dependency, scale framing, and cross-scale interactions in collaborative conservation. Journal of Environmental Management 123:58-67. http://dx.doi.org/10.1016/ j.jenvman.2013.03.014 